УДК 622.834.2:622.862.3

DOI: https://doi.org/10.26642/ten-2019-2(84)-137-148

С.В. Подкопаев, д.т.н., проф.

В.Б. Гого, д.т.н., проф.

И.В. Иорданов, к.т.н., доц.

А.В. Положий, аспир.

Ю.И. Симонова, аспир.

ДВНЗ «Донеикий начиональный технический университет»

\title{
Обоснование условий устойчивости откаточных штреков в глубоких шахтах
}

Цель исследования - обосновать условия устойчивости и особенности проявлений горного давления на контуре участковых подготовительных выработок при разных способах охраны в глубоких шахтах.

Используется комплексный подход, включающий анализ и обобщение теоретических $u$ экспериментальных исследований по проблеме устойчивости выемочных подготовительных выработок, при разных способах охраны, на шахтах, разрабатывающих пласты крутонаклонного и крутого залегания на больших глубинах.

В результате выполненных экспериментальных и аналитических исследований установлено, что при охране откаточных шттреков податливыми охранными сооружениями (накатные костры из деревянных шпал) нагрузка на крепь подготовительной выработки с течением времени, по мере подвигания лавы, стремится по гиперболической зависимости к конечной величине. При этом происходит изменение ее прироста, а смещения боковых пород на контуре откаточного штрека принимают наибольшие значения в начальный период времени после выемки угля. Однако при охране выработки хрупкими охранными сооружениями - иеликами угля, изменение прироста нагрузки на крепь в единииу времени происходит по линейному закону, что приводит к ухудшению устойчивости откаточного штрека позади очистного забоя, связанного с потерей несущей способности крепи, предназначенной для поддержания подготовительной выработки.

Условия устойчивости откаточного штрека основываются на представлении крепи, установленной в выемочной выработке, в виде геометрически неизменяемой системы, отдельные элементы которой испытывают деформации изгиба от действия внешних сил, проявляюшихся при разгрузке углепородного массива, в результате ведения горных работ.

Для повыщения безопасности труда горнорабочих в глубоких шахтах, необходимо применять податливые сооружения или закладку выработанного пространства для охраны откаточных штреков, на основе повышения их устойчивости, что обеспечивает их эксплуатационное состояние позади очистного забоя.

Ключевые слова: горное давление; обрушения; очистной забой; боковые породы; динамические нагрузки; податливая опора; закладка выработанного пространства; деформации; перемещение; способ охраны.

Введение. Актуальность исследования обусловлена тем, что разработка угольных пластов Донбасса характеризуется относительно низким уровнем технико-экономических показателей. В немалой степени это связано с отсутствием надежных и эффективных средств и способов обеспечения устойчивости боковых пород и горных выработок. Научные исследования и опыт работы глубоких шахт показывает, что с ростом глубины в массиве осадочных горных пород возникает негативный фактор - расслоение кровли и почвы угольного пласта, оказывающие отрицательное влияние на состояние горных выработок. Применяемые способы охраны выемочных подготовительных выработок, являясь результативными в отдельных горно-геологических условиях, теряют свою эффективность при изменении этих условий, что создает аварийные ситуации для ведения работ.

При разработке наклонных и крутых угольных пластов возникают опасности обрушений и обвалов не только пород кровли, но и сползаний пород почвы. В одних случаях обрушения и обвалы боковых пород распространяются на призабойное пространство лавы, часто по всей ее длине, и сопровождаются частичным или полным завалом очистного забоя и подготовительных выработок. В других случаях эти явления происходят за лавой и приводят только к завалу подготовительных выработок. Во всех приведенных случаях имеет место потеря регламентированного Правилами безопасности сечения штреков, что в свою очередь, способствует увеличению уровня травматизма на протяжении горных выработок. Поэтому разработка эффективных мероприятий, направленных на поддержание штреков в эксплуатационном состоянии, является актуальной научно-технической задачей и отвечает требованиям безопасного ведения горных работ в глубоких угольных шахтах. 
Анализ исследований и публикаций. Переход горных работ на глубину более 1000 м привел к значительному росту горного давления, что вызывает увеличение смещений пород на контуре подготовительных выработок в 2,2-2,5 раза. С увеличением глубины горных работ, в зонах разгрузки, формируются условия обрушений кровли и сползаний почвы, что приводит к потере устойчивости и завалам горных выработок [1].

По мере выемки угля подработанные породы, оседающие на хаотически обрушенные слои расслоившейся толщи, представляют собой блочный массив, состоящий из балок различной длины. Причем, в результате расслоения породы кровли изгибаются, неконтролируемо оседают позади очистного забоя и создают неблагоприятную геомеханическую обстановку в окрестности поддерживаемых горных выработок $[2,3]$. Установлено [4], что в зависимости от горно-геологических условий, зона расслоения боковых пород в кровлю и почву разрабатываемого угольного пласта, составляет по нормали к напластованию, 4-5 м. Негативные последствия такой геомеханической обстановки могут проявляться в том, что кровля, не имея достаточного подпора в выработанном пространстве, внезапно обрушается, в результате чего крепь деформируется и происходит потеря площади поперечного сечения откаточного штрека $[1,5]$.

Считается [6, 7], что при наклонном залегании угольных пластов и на крутом падении можно принимать давление на крепь откаточного штрека, как действие консольной балки, претерпевшей излом у угольного массива. Помимо того, на состояние подготовительных выработок определяющее влияние оказывают сдвижения боковых пород в лаве, в результате чего так же происходит формирование нагрузки на крепь [7]. В таких условиях противостоять смещениям на контуре выработки в процессе ее поддержания, особенно в зонах активного влияния горного давления, только при помощи арочной крепи практически невозможно [4]. Проведение полевых участковых выработок облегчает условия их поддержания, по сравнению с пластовыми, но при этом конструктивно усложняется система разработки пластов и увеличивается относительный объём проводимых участковых выработок.

Известно $[1,2,4,8]$, что эффективность отработки угольных пластов и безопасность ведения горных работ в глубоких шахтах, в значительной степени зависит от способа управления кровлей в лаве и охраны подготовительных выработок. В связи с этим, изучение процесса сдвижений боковых пород, определение величины смещений на контуре выемочных штреков, а также правильное понимание при этом геомеханических процессов позволит обосновать выбор рационального способа охраны участковых подготовительных вырабок, в конкретных горно-геологических условиях разработки угольных пластов. В связи с тем, что учесть все многообразие факторов, оказывающих влияние на состояние штреков при ведении очистных работ, практически невозможно, предлагается условия их поддержания оценивать по величине сближения пород контура и изменению площади поперечного сечения выемочной подготовительной выработки.

Постановка задачи исследований. Изучить особенности проявлений горного давления на контуре участковых подготовительных выработок при разных способах охраны. Для достижения поставленной цели и решения задачи были выполнены натурные исследования по наблюдению за смещением боковых пород на контуре пластового откаточного штрека при разных способах охраны и определен параметр нагрузки, при которой происходит разрушение контура выемочной выработки и потеря несущей способности крепи, установленной в откаточном штреке.

Изложение основного материала. Закономерности периодического характера проявления горного давления в подготовительных выработках и определение величины смещений боковых пород на их контуре, при разных способах охраны, экспериментально исследованы в условиях ГП «Торецкуголь» на шахтах «Торецкая» и «Центральная» [9].

При проведении экспериментальных наблюдений в откаточном штреке, на специально оборудованных замерных станциях устанавливалась величина смещения контрольных точек, за промежуток времени между замерами. Схема экспериментального участка представлена на рисунке 1.

На специально оборудованной замерной станции, с помощью рулетки ВНИМИ, определялась величина смещения боковых пород на контуре выработки, когда устанавливали величину сближения реперов относительно друг друга, по наиболее характерным для наклонного и крутого падения направлениям. Погрешность замеров не превышала \pm 2 мм. Схема расположения реперов замерных станций представлена на рисунке 2.

Исследования проводились в откаточном штреке, пройденном по пласту $1_{3}$ Мазурка горизонта 810 м шахты «Торецкая», на участке длиной $1=70 \mathrm{M}$, когда штрек охранялся деревянными кострами и на участке длиной $1=100$ м, при охране этого штрека целиками угля. Площадь поперечного сечения штрека составляла $S=8,2 \mathrm{M}^{2}$, расстояние между рамами арочной крепи АП-3 с деревянной затяжкой - 0,8 м. Штрек проводился с помощью буровзрывных работ (БВР). Скорость проведения штрека $\mathrm{v}_{ш}=10 \mathrm{м} / \mathrm{мес.,} \mathrm{скорость}$ очистных работ $\mathrm{v}_{ш}=7 \mathrm{M} / \mathrm{меc}$. Лава с потолкоуступным забоем. Способ управления кровлей в лаве удержание на кострах. Охрана штрека осуществлялась деревянными кострами, а через некоторое время, в связи с ухудшением горно-геологических условий - целиками угля, размер которых $\mathrm{h}_{\mathrm{L}}=8 \mathrm{M}, 1_{\mathrm{L}}=5 \mathrm{M}$, где $\mathrm{h}_{ц}-$ высота целика, м; $1_{ц}-$ ширина целика, м. 
Эксперименты в условиях шахты «Центральная» были проведены в откаточном штреке пласта $1_{3}$ горизонта 1146 м на участке длиной $1=55$ м при охране штрека кустокострами и на участке, длина которого $1=78$ м, когда штрек охраняли целиками угля. Площадь поперечного сечения штрека $\mathrm{S}=8,5 \mathrm{M}^{2}$, расстояние между рамами крепи АП-3 с деревянной затяжкой - 0,8 м. Штрек проводился с помощью БВР. Скорость проведения штрека $\mathrm{V}_{ш}=18 \mathrm{~m} / \mathrm{меc.,} \mathrm{скорость} \mathrm{очистных} \mathrm{работ} \mathrm{v}_{\text {оч. }}=12 \mathrm{M} /$ мес. Штрек охраняли кустокострами, а затем целиками угля, размер которых соответствовал $\mathrm{h}_{ц}=8$ м, $\mathrm{l}_{ц}=5 \mathrm{~m}$.

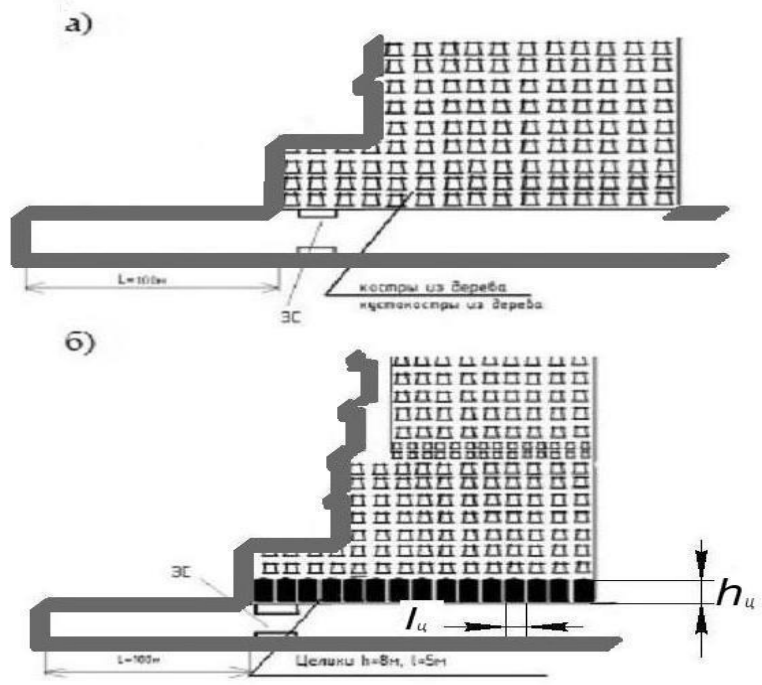

Рис. 1. Схема экспериментальных участков для определения смещений боковых пород на контуре откаточного штрека, пройденного по пласту $l_{3}$ «Мазурка» при охране (а) деревянными кострами или кустокострами, (б) целиками угля: 3С-место расположения замерной станичи; $h_{u}, l_{u}$-соответственно, высота и ширина угольного целика, м

a)

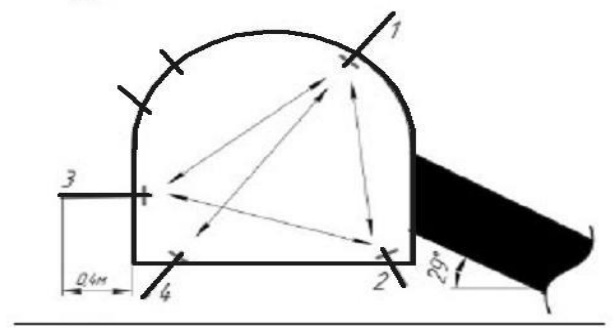

6)

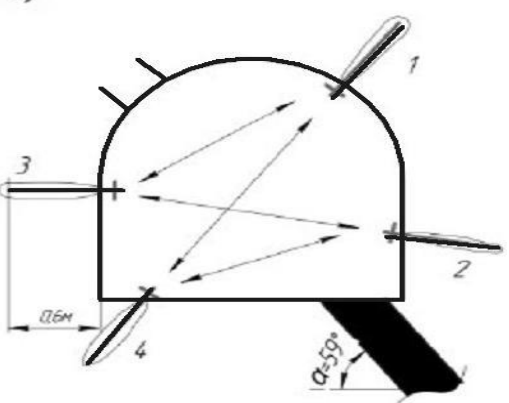

Рис. 2. Схемы замерных станиий для определения смещений боковых пород на контуре откаточного штрека, пройденного по пласту $l_{3}:$ а) на горизонте 810м шахты «Тореиякая»; б) на горизонте $1146 \mathrm{м}$ шахты «Центральная»; 1, 2, 3, 4-репера; 1-3, 1-4, 1-2, 2-3, 2-4-сближение реперов 1, 2 в направлении реперов 3,4

Мощность угольного пласта $1_{3}$ в условиях шахты «Торецкая» $\mathrm{m}=1,32$ м, угол падения пласта $\alpha=29^{\circ}$. В непосредственной кровле залегает глинистый сланец, средней устойчивости, мощностью до $\mathrm{m}=4,0 \mathrm{M}$. Основная кровля представлена песчанистым сланцем, мощностью до $\mathrm{m}=10$ м. В непосредственной почве, залегает глинистый сланец средней устойчивости, мощностью до $\mathrm{m}=1,5$ м, в основной - глинистый сланец, мощностью до $\mathrm{m}=4,1$ м. Опережение штрека составляло $\mathrm{L}=100$ м. 
Мощность угольного пласта $l_{3}$ в условиях шахты «Центральная» $\mathrm{m}=1,17$ м, угол падения пласта $\alpha=59^{\circ}$. В непосредственной кровле залегает глинистый сланец, мощностью до $\mathrm{m}=4,0$ м, в основной сланец песчанистый, мощностью до $\mathrm{m}=7,0$ м. В почве пласта залегает глинистый сланец, мощностью до $\mathrm{m}=15,0$ м. На момент выполнения экспериментов, опережение штрека составляло $L=100 \mathrm{M}$.

При проведении натурных наблюдений основное внимание уделялось смещению пород на контуре подготовительных выработок при разных способах охраны, в зависимости от расстояния до очистного забоя. По результатам обработки экспериментальных данных были построены графики смещений пород на контуре откаточного штрека пласта $1_{3}$ Мазурка горизонта 810 м шахты «Торецкая» при его охране деревянными кострами (рис. 3 a) или целиками угля (рис. 3 б).

a)

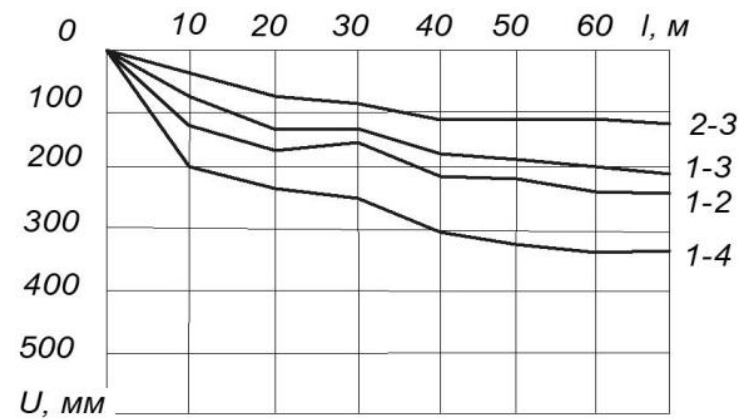

б)

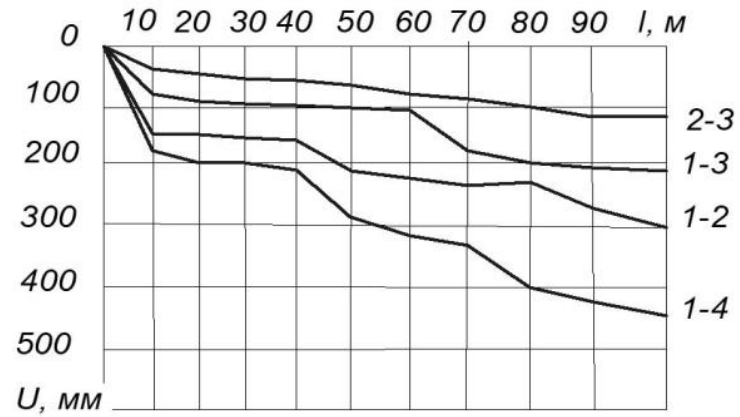

Pис. 3. Смещения пород U, (мм) на контуре откаточного шттека пласта $l_{3}$ по длине l, (м) горизонта 810 м шахты «Тореичкая»: а) при охране деревянными кострами; б) при охране ичеликами угля

В результате выполненных замеров в откаточном штреке пласта $l_{3}$ шахты «Торецкая» было установлено, что максимальные величины смещений на контуре подготовительной выработки, при ее охране деревянными кострами, отмечены на расстоянии $l=70$ м позади очистного забоя, в направлениях реперов 1-4 и 1-2. В этом месте величина сближения реперов, по указанным направлениям, составляла соответственно, $\mathrm{U}_{1-4}=340$ мм, и $\mathrm{U}_{1-2}=250$ мм (рис.3 a). При охране штрека целиками угля, максимальные смещения были зарегистрированы на расстоянии $l=100$ м позади лавы, по направлениям 1-4 и 1-2. В количественном выражении, величина смещений в направлении реперов $1-4$ составляла $U_{1-4}=440$ мм, в направлении реперов $1-2-\mathrm{U}_{1-2}=300$ мм (рис. 3 б).

Важным является факт, что одновременно с фиксированием сближения реперов на контуре подготовительной выработки регистрировалось изменение площади поперечного сечения штрека $\mathrm{S},\left(\mathrm{M}^{2}\right)$, для чего были выполнены замеры ширины b, (м) и высоты h, (м), поддерживаемой позади лавы, пластовой подготовительной выработки. По результатам замеров, на рисунке 4 представлены графики изменений площадей поперечных сечений штрека $\mathrm{S},\left(\mathrm{M}^{2}\right)$ по его длине, при разных способах охраны, с учетом подвигания очистного забоя.

Из представленных зависимостей следует, что при охране штрека деревянными кострами, его сечение $\mathrm{S},\left(\mathrm{M}^{2}\right)$ изменилось с $\mathrm{S}=8,2 \mathrm{~m}^{2}$ до $\mathrm{S}=6,0 \mathrm{~m}^{2}$ на расстоянии $l=65$ м позади лавы, т. е. уменьшение составило до 25 \%. В дальнейшем, за указанной отметкой, конвергенции боковых пород не наблюдалось (рис. 4,

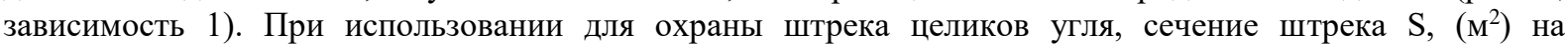
протяжении $l=100$ м изменилось с $\mathrm{S}=8,5 \mathrm{~m}^{2}$ до $\mathrm{S}=3,6 \mathrm{~m}^{2}$ (рис. 4, зависимость 2). В этом случае уменьшение составило до $60 \%$. 


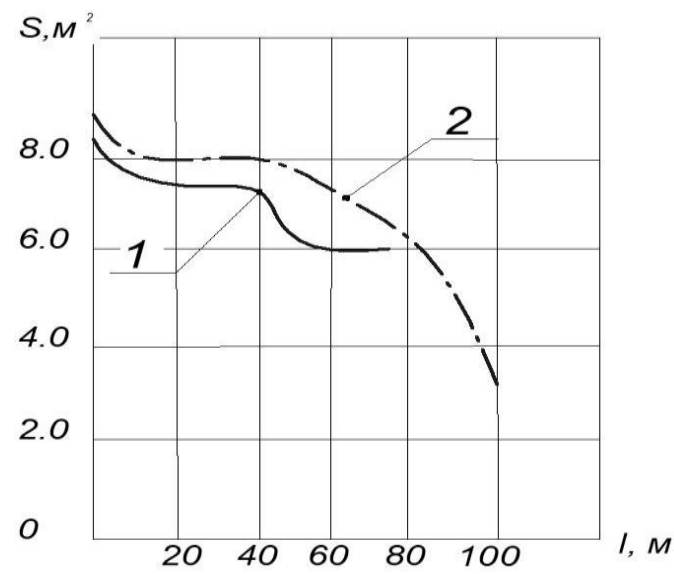

Pис. 4. Изменения площади поперечного сечения $S$, ( м $\left.^{2}\right)$ откаточного штрека пласта $l_{3}$ по длине $l$, (м) на горизонте 810 м шахты «Торецкая» при охране: 1 - деревянными кострами; 2 - иеликами угля

Данные обработки экспериментальных показателей смещений пород, полученных в условиях шахты «Центральная», когда откаточный штрек пройденный по пласту $1_{3}$ на горизонте 1146 м, охранялся кустокострами или целиками угля, представлены в виде зависимостей, изображенных на рисунке 5.

По результатам замеров сближения реперов в выработке установлено, что максимальные смещения, при охране штрека кустокострами, отмечены на расстоянии $l=55$ м позади очистного забоя, по направлениям 1-4 и 1-3, когда $\mathrm{U}_{1-4}=350$ мм, $\mathrm{U}_{1-3}=290$ мм (рис. 5 a). При переходе на другой способ охраны - целики угля, сближения реперов по этим направлениям составили, соответственно, $U_{1-4}=440$ мм, и $\mathrm{U}_{1-3}=320$ мм, на расстоянии $l=75$ м позади очистного забоя (рис. 5 б).

a)

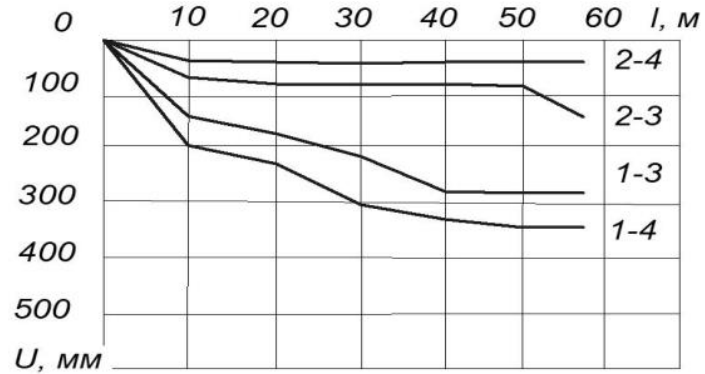

б)

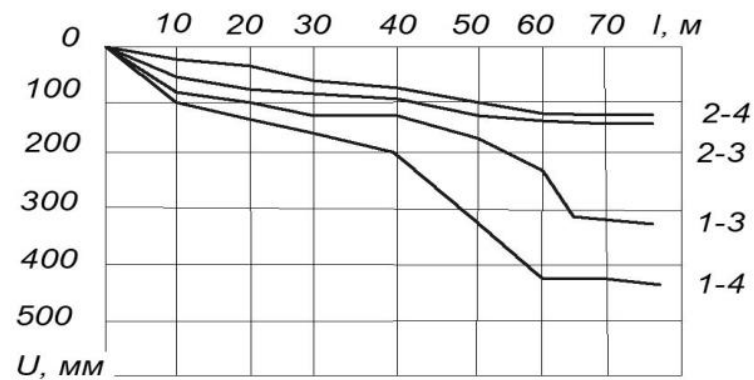

Puc. 5. Смещения пород U, (мм) на контуре откаточного штрека пласта $l_{3}$ по длине l, (м) на горизонте 1146 м шахты «Центральная»: а) при охране кустокострами; б) при охране целиками угля

Анализируя изменение площади поперечного сечения штрека $\mathrm{S},\left(\mathrm{M}^{2}\right)$ по длине было установлено, что при охране пластовой подготовительной выработки кустокострами ее сечение уменьшилось с $\mathrm{S}=8,5 \mathrm{~m}^{2}$ до $\mathrm{S}=6,8 \mathrm{~m}^{2}$ на расстоянии $l=55$ м позади очистного забоя (рис. 6, зависимость 1 ). При использовании для охраны откаточного штрека целиков угля сечение штрека $\mathrm{S},\left(\mathrm{м}^{2}\right)$ изменилось с $\mathrm{S}=8,6 \mathrm{м}^{2}$ до $\mathrm{S}=5,5 \mathrm{м}^{2}$ на протяжении $l=75$ м (рис. 6, зависимость 2). Следует отметить, что уменьшение площади поперечного сечения $\mathrm{S},\left(\mathrm{M}^{2}\right)$ в первом случае составило $20 \%$, во втором - $35 \%$. 
При проведении экспериментальных исследований за смещением пород на контуре откаточного штрека по характерным для крутонаклонного и крутого падения направлениям установлено, что наибольшие сближения реперов имеют место со стороны кровли пласта, в результате чего применяемая, для поддержания штрека арочная крепь деформируется, а следовательно, уменьшается площадь поперечного сечения выработки. Характерно, что сдвижения пород со стороны висячего бока, во всех случаях, были представлены послойным изгибом кровли. Глинистый сланец, залегающий в породах непосредственной кровли, был разбит серией трещин, в результате чего, в некоторых случаях, имело место высыпание породы в штрек.

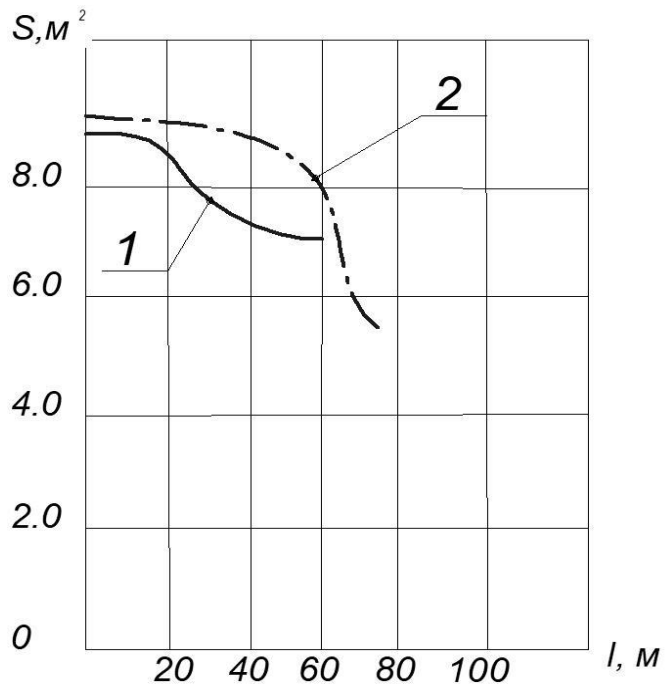

Рис. 6. Изменения площчади поперечного сечения $S$, $\left(\mathrm{M}^{2}\right)$ откаточного шттрека пласта $l_{3}$ по длине l, (м) на горизонте 1146 м шахты «Центральная» при охране: 1 - кустокострами; 2 - целиками угля

При охране выемочной подготовительной выработки деревянными конструкциями, за отметкой $l=50$ м позади очистного забоя, сдвижения боковых пород практически затухают и стабилизируются. В случае оставления для охраны выработок целиков угля такая закономерность не прослеживается. Тем не менее характер сдвижения боковых пород на контуре выработки, с удалением от очистного забоя в сторону выработанного пространства, имеет одинаковую качественную картину, но отличается интенсивностью.

Анализ и аналитическая обработка экспериментов.

Очевидно то, что в реальных условиях разработки угольных пластов, при разных способах управления кровлей в лаве и охраны откаточных штреков, сохранность выемочных подготовительных выработок, обеспечивается за счет устойчивости пород кровли как основного грузонесущего элемента подземного сооружения.

Известно [2, 6], что при ведении горных работ, в углепородном массиве, вмещающем выработки, происходит последовательное отделение слоев от вышележащей толщи и их прогиб по нормали к напластованию, подобно балке имеющей опоры. Согласно гипотезе балок [6, 7] считается, что кровля угольного пласта деформируется и разрушается подобно балке, которая под воздействием внешних нагрузок превращается в механизмы, в результате достижения изгибающими моментами предельных величин [10-13].

Исходя из результатов натурных наблюдений, выполненных в участковых подготовительных выработках, исследуем возможные механизмы разрушения контура выработки и деформации крепи, рассматривая крепь откаточного штрека как геометрически неизменяемую систему, способную воспринимать действующие на нее нагрузки. Данное допущение превращает арку в систему, состоящую из балок, с постоянным значением изгибающих моментов. В качестве неизвестных, при решении такой задачи, принимаются деформации опорных точек, которые располагаются по контуру выработки. Отличительной особенностью расчета принятой системы крепления является наличие погрешности, связанное с разделением арочной формы сечения откаточного штрека на прямолинейные участки.

Исследуем модель откаточного штрека для определения предельной нагрузки на крепь выработки кинематическим способом $[10,14,15]$ по схеме, представленной на рисунке 7.

Используя основные положения теории предельного равновесия, считаем, что принятая модель крепи в откаточном штреке рассматривается в момент, непосредственно предшествующий разрушению контура выработки, когда еще выполняются условия равновесия для внутренних и внешних сил, достигших 
предельных значений $[15,16]$. Для такой системы, работающей преимущественно на изгиб, разрушение контура выработки определяется, в основном, величиной изгибающего момента, возникающего в породах кровли при разгрузке углепородного массива.

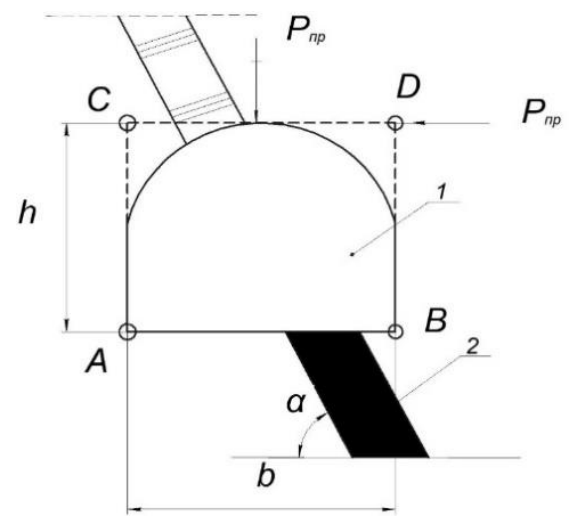

Рис. 7. Схема модели откаточного штррека для определения предельной нагрузки на крепь выработки: 1 - откаточный штррек; 2 - угольный пласт; $P_{n p}$ - предельная нагрузка, $(H) ; \alpha$-угол падения пласта, (град), A, B, C, D-опорные точки; $h, b$-соответственно, высота и ширина откаточного шттрека, (м)

Решим задачу определения предельной нагрузки $\mathrm{P}_{\text {пр }}$, $(\mathrm{H})$ на конструкцию крепи, изображенную на рисунке $8 a$, с учетом принятых механизмов деформирования (рис. $86,6,2$ ). Такой подход к решению задачи о предельном состоянии крепи в откаточном штреке дает нижнюю оценку предельной нагрузки. Величину нагрузки, для статически неопределимой системы с опорными точками, можно определить исследуя различные варианты распределения усилий. Считаем, что поперечное сечение всех элементов крепи в рассматриваемой модели одинаковое.

Исследуем несколько вариантов трансформации конструкции крепи в механизмы (рис. 8 б, 6,2 ).

1. Принимаем, что пластические шарниры образуются в узлах и сечениях элемента крепи выработки (рис. 8 б).

Значит

$$
\begin{aligned}
& P_{\text {пр }} \cdot h \cdot \varphi-4 M_{\text {и }} \cdot \varphi=0, \\
& P_{\text {пр }}=\frac{4 M_{\text {и }}}{h},
\end{aligned}
$$

где $h$ - высота выработки, м;

$\varphi$ - угол поворота в опорных точках;

$M_{\text {и }}-$ изгибающий момент, Н·м.
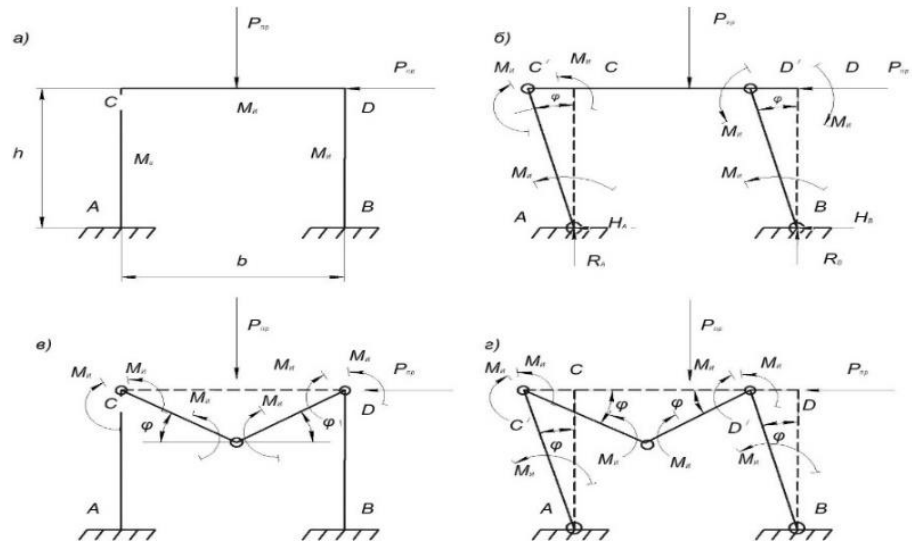

Рис. 8. Схема принятых механизмов деформирования крепи откаточного штрека: а) общая схема;

б) смещение опорных точек $C$ и $D$; в) балочный механизм деформирования верхняка крепи;

г) комбинированный механизм деформирования; $A, B, C, D$-опорные точки; $P_{n p}$ - предельная нагрузка,

(H); $\varphi$-угол поворота в опорных точках, (град); $M_{u}-$ изгибающий момент, $(H \cdot M) . R_{A}, R_{B}, H_{A}, H_{B}-$ реакиия опоры $А$ и $B$, (H) 
2. Принимаем балочный механизм деформирования верхняка крепи (рис. 8 в).

Имеем

$$
P_{\text {пр }} \cdot \frac{b}{2} \cdot \varphi-4 M_{\text {и }} \cdot \varphi=0,
$$

$$
P_{\text {пр }}=\frac{8 M_{\text {и }}}{b}
$$

где $b$ - ширина выработки, м.

3. Принимаем комбинированный механизм деформирования крепи выработки (рис. 8 г).

Очевидно то, что

$$
P_{\text {пр }} \cdot h \cdot \varphi+P_{\text {пр }} \cdot \frac{b}{2} \cdot \varphi-6 M_{\text {и }} \cdot \varphi=0,
$$

и

$$
P_{\text {пр }}=\frac{6 M_{\text {и }}}{h+\frac{b}{2}}=\frac{12 M_{\text {и }}}{2 h+b} \text {. }
$$

Минимальное значение предельной нагрузки на крепь откаточного штрека $\mathrm{P}_{\text {пр}},(\mathrm{H})$, обеспечивается в случае, изображенном на рисунке 8 б. Из этого следует, что действительный механизм разрушения контура выработки и деформирования крепи имеет место при предельной нагрузке на крепь откаточного штрека, когда выполняется условие

$$
P_{\text {пр }}=\frac{4 M_{\text {и }}}{h} .
$$

Следует отметить, что кинематический метод предполагает освобождение моделируемой системы от некоторой связи и рассмотрение в образованной системе виртуальных перемещений. Однако длина пути, на которой сравниваются работы сил при изучении механизмов деформирования крепи, в результате действия нагрузки не имеет значения, что следует из теоремы Бетти о взаимности работ [15, 16]. Значит, величина перемещения $\mathrm{CC}^{\prime}$ и $\mathrm{DD}^{\prime}$ (рис. 8 б, г), не влияет на условия разрушения контура выработки и деформирования крепи.

Проверим правильность решения задачи. Согласно статической теореме $[15,16]$, при $\mathrm{P}_{\text {пр }}(\mathrm{H})$, должна выполняться система уравнений равновесия, когда

$$
\begin{aligned}
& \sum M_{A}=0 ; \quad P_{\text {пр }} \cdot h+P_{\text {пр }} \cdot \frac{b}{2}-M_{\text {и }} \cdot 2-R_{B} \cdot b=0 . \\
& \sum M_{C}=0 ; \quad P_{\text {пр }} \cdot \frac{b}{2}-R_{B} \cdot b+H_{\text {А }} \cdot h=0 . \\
& \sum M_{D}=0 ; \quad H_{B} \cdot h-2 M_{\text {и }}=0 .
\end{aligned}
$$

Решив систему уравнений (8), получим выражение (7), для определения $P_{\text {пр }},(\mathrm{H})$, что свидетельствует о том, что кинематически возможное состояние рассматриваемой конструкции является и статически возможным, а значит, механизм разрушения контура выработки и деформирования крепи является идентичным. Очевидно и то, что предельной нагрузкой, будет нагрузка, соответствующая исчерпанию несущей способности крепи, когда не происходит потери устойчивости в эйлеровом смысле.

В теории предельного равновесия, кинематическую свободу обеспечивает пластический шарнир, в котором изгибающий момент равен предельному $[10,14,15]$. Определим величину предельного изгибающего момента, как это рекомендуется в [17], по выражению

- для податливых охранных сооружений

$$
\mathrm{M}_{\text {и }}=\frac{3 E I}{L^{2}} \cdot U_{1-4}
$$

- при охране целиками угля

$$
\mathrm{M}_{\text {и }}=\frac{6 E I}{L^{2}} \cdot U_{1-4}
$$

где Е - модуль упругости пород непосредственной кровли, Н/м²;

I - момент инерции площади исследуемого поперечного сечения элемента крепи, $\mathrm{M}^{4}$;

$\mathrm{L}$ - длина консольной части балки, поддерживаемой охранным сооружением, м;

$U_{1-4}-$ смещения репера 1 в направлении репера 4 , м. 
Для экспериментальной проверки изложенных аналитических исследований на рисунке 9 представлены графики изменений нагрузки $P_{\text {пр }},(\mathrm{H})$, на контуре откаточного штрека по его длине $1,(\mathrm{M}), \mathrm{c}$ учетом выражений (9) и (10), при охране подготовительной выработки деревянными кострами и целиками угля, в условиях шахт ГП «Торецкуголь».

В результате выполненных исследований установлено, что для податливых охранных сооружений, характерно их пластическое деформирование с плавным увеличением нагрузки на крепь выработки до максимальных значений. При определении величины предельной нагрузки на крепь откаточного штрека, при его охране податливыми сооружениями, нагрузка может считаться переменной во времени, до момента полного сжатия опоры. В этих случаях изогнутая гиперболическая ветвь графика, изображенная на рисунках $9 a$, б (зависимость 1), характеризует увеличение нагрузки до значений $P_{\text {пр }}=9,8 \cdot 10^{6} \mathrm{H}$. Такое увеличение отмечено на расстоянии до $1=40-50$ м позади лавы (рис. $9 a$, б). За отметкой $1>50$ м, создаются условия, когда в зоне установившегося горного давления нагрузка на крепь выработки не увеличивается. Однако, в некоторых случаях, изменение площади поперечного сечения выемочной подготовительной выработки при отсутствии приращения нагрузки может рассматриваться как потеря устойчивости откаточного штрека, связанная с потерей несущей способности арочной крепи, предназначенной для его поддержания.

a)

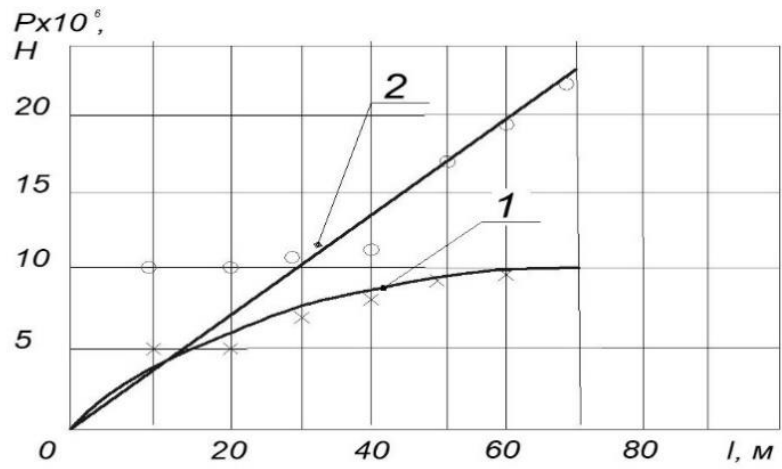

б)

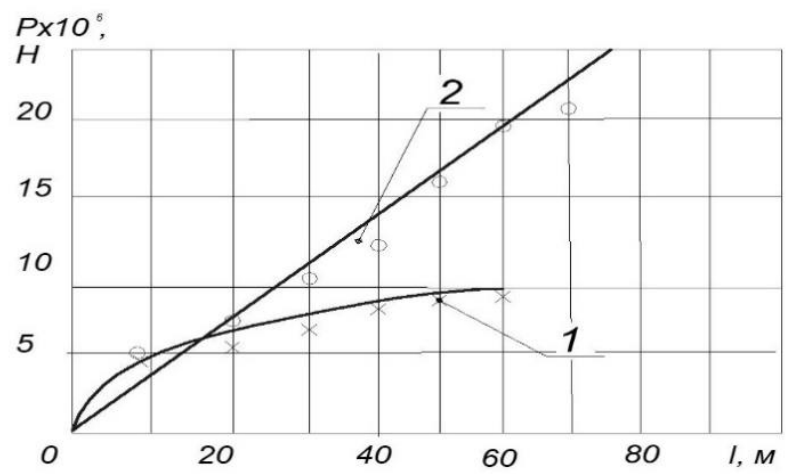

Рис. 9. Графики изменений предельной нагрузки $P_{\text {пр }}$, (H) на крепь откаточного штрека по его длине l, (м) при охране: 1 - деревянными кострами; 2 - целиками угля; в условиях шахты а) «Тореикая», б) «Центральная», когда $L=10 \mathrm{M}, E=9200 \mathrm{M \Pi а}, \mathrm{I}=0,083 \mathrm{~cm}^{4}$

Ранее, в работах $[8,9,18-21]$ было установлено, что угольные целики представляют собой хрупкое охранное сооружение, работа которого не предполагает возникновения пластических деформаций, а значит, при охране откаточного штрека целиками угля их разрушение и разрушение кровли угольного пласта, приводит к усиленной деформации крепи и уменьшению площади поперечного сечения выработки, о чем свидетельствуют данные замеров (рис. 3-6) и зависимость 2, представленная на рисунках $9 a$, б . Очевидно то, что при сближении боковых пород на контуре откаточного штрека крепь выработки находится под воздействием продольных сил и изгибающих моментов. При малых нагрузках влияние продольных сил на деформацию крепи невелико и приращения перемещений почти пропорциональны приращениям нагрузок. Однако по мере подвигания лавы и разрушения целика нагрузка увеличивается, влияние продольных сил возрастает и уменьшение площади поперечного сечения откаточного штрека происходит одновременно с деформацией крепи (рис. $9 a, \sigma$ ).

Таким образом, не отвергая принципиальную возможность улучшения состояния откаточных штреков за счет повышения несущей способности крепей, все же основным направлением, обеспечивающим сохранность выработок в эксплуатационном состоянии, которое отвечает требованиям Правил 
безопасности, следует считать поиск более надежных и конструктивно простых способов охраны, когда подработанная нависающая толща пород поддерживается на значительной отработанной площади, позади лавы. При обосновании условий устойчивости откаточных штреков в глубоких шахтах, необходимо учитывать, что нагрузка на крепь выемочной подготовительной выработки, которая стабилизируется или возрастает, на различном расстоянии от очистного забоя в сторону выработанного пространства, в зависимости от типа охранного сооружения.

В этом случае, применение закладки выработанного пространства оказывает, в сравнении с другими способами охраны штреков и управления кровлей в лаве, более заметное положительное влияние на состояние боковых пород, в т. ч. пород кровли, и способствует улучшению геомеханической обстановки в окрестности очистного забоя, а также в прилегающих к нему пластовых подготовительных выработках.

Вывод. Экспериментально-аналитически обосновано, что при охране участковых подготовительных выработок податливыми охранными сооружениями, нагрузка на крепь выработки, с течением времени, стремится к конечной величине, а изменение ее прироста в единицу времени имеет гиперболический характер. В результате такого взаимодействия оседающих пород кровли с податливым охранным сооружением, смещения пород в выработку, а следовательно, нагрузка на крепь откаточного штрека, будут наибольшими в начальный период времени после выемки угля. При охране откаточного штрека хрупкими охранными сооружениями - целиками угля, изменение прироста нагрузки на крепь выработки в единицу времени, происходит по линейному закону, что обусловливается разрушением целика. В условиях глубоких шахт, для обеспечения эксплуатационного состояния подготовительных выработок, целесообразно применение для их охраны податливых сооружений или закладки выработанного пространства при ведении очистных работ, что обеспечивает плавный прогиб подработанной породной толщи позади очистного забоя и сохранность откаточных штреков.

\section{Список использованной литературы:}

1. Николин В.И. Снижение травматизма от проявлений горного давления / В.И. Николин и др. - Донецк : НордПресс, 2005. - $332 \mathrm{c}$.

2. Викторов С.Д. Сдвижение и разрушение горных пород / С.Д. Викторов, М.А. Иофис, С.А. Гончаров. - М. : Наука, 2005. - $277 \mathrm{c}$

3. Жуков B.E. Об одной стратегической ошибке в разрешении проблемы разработки крутых пластов / B.E. Жуков // Уголь Украины. - 2001. - № 7. - С. 6-10.

4. Селезень А.Л. Поддержание подготовительных выработок при разработке крутых пластов / А.Л. Селезень, А.Г. Томасов, В.Ф. Андрушко. - М. : Недра, 1977. - 205 с.

5. Радченко B.B. Предотвращение травматизма от обвалов и обрушений на угольных шахтах. / B.B. Радченко, Э.Н. Медведев, Н.С. Кузьменко. - К., 2010. - 372 с.

6. Шашенко А.Н. Геомеханика / А.Н. Шашенко, В.П. Пустовойтенко, Е.А. Сдвижикова. - К. : Науковий друк, 2016. $-528 \mathrm{c}$.

7. Борисов А.А. Механика горных пород и массивов / А.А. Борисов. - М. : Недра, 1980. - 360 с.

8. Experimental studies of the seam openings competence in different methods of protection under pitch and steep coal seams development / Ya.Liashok, I.Iordanov, D.Chepiga, S.Podkopaiev // Mining of Mineral Deposits. - 2018. Vol. 12. - Issue 4. - P. 9-19.

9. Исследование проявлений горного давления в подготовительных выработках с учетом жесткости охранных сооружений / С.В. Подкопаев, Е.И. Конопелько, Д.А. Чепига, и др. // Вісті Донецького гірничого інституту. 2018. - № 1 (42). - С. 84-95.

10. Ржаницын Р.А. Строительная механика / Р.А. Ржаницын. -М. : Высшая школа, 1982. - 398 с.

11. Соколовский В.В. Теория пластичности / В.В. Соколовский. - М. : Высшая школа, 1969. - 608 с.

12. Barant Z.P. Stability of structures: elastic, inelastic, fracture, and damage theories / Z.P. Barant, L.Cedolin. - World Scientific Publishing Co. Pte. Ltd., 2010. - 1039 p.

13. Dakhakhi W. Theory of Structures / W.Dakhakhi. - Dal Al- Maaref. - 2010. $-446 \mathrm{p}$.

14. Marti P. Theory of Structures: Fundamentals, Framed Structures, Plates and Shells / P.Marti. - John Wiley Sons. Inc., Ernst Sohn GmbH\&Co. KG, 2013. - 679 p.

15. Яровая А.В. Строительная механика. Статика стержневых систем / А.В. Яровая. - Гомель : БелГУТ, 2013. $447 \mathrm{c}$.

16. Лещенко А.П. Фундаментальная строительная механика упругих систем / А.П. Лещенко. - М. : ЛКИ. - 2008. $976 \mathrm{c.}$

17. Влияние податливости опор на устойчивость пород кровли угольного пласта / И.В. Иорданов, Ю.И. Симонова, А.В. Положий и др. // Proceedings of the XIII International Scientific and Practical Conference International Trends in Science and Technology. - Vol. 1. - P. 52-60.

18. Фекмистов Ю.Г. Обоснование распределения давления на целики в осадочных горных породах / Ю.Г. Фекмистов, А.Д. Головин // Литосфера. - 2015. - № 6. - С. 130-135.

19. Effects of fracture geometry and stress on the strength of a fractured rock mass / A.Khari, A.Baghbanan, S.Norouzi, H.Hashemolhosseini // International Journal of Rock Mechanics\&Mining Sciences. - 2013. - № 60. - P. 345-352.

20. Протосеня А.Г. Расчет несущей способности и изучение анизотропии прочностных характеристик междукамерных целиков в блочном горном массиве / А.Г. Протосеня, П.Э. Вербило // Сборник трудов (VIII Международная научно-практическая конференция «Инновационные направления в проектировании 
горнодобывающих предприятий: Геомеханическое обеспечение проектирования и сопровождения горных работ»). - Санкт-Петербург, 2017. - С. 219-225.

21. Chenlong $W$. Dynamic structural evolution of overlying strata during shallow coal seam longwall mining / Chenlong Wanga, Changsuo Zhanga, Xiaodong Zhaob and other // International Journal of Rock Mechanics and Mining Sciences. - 2018. - Vol. 103. - P. 20-32.

\section{References:}

1. Nikolin, V.I. i dr. (2005), Snizhenie travmatizma ot proyavlenii gornogo davleniya, Nord-Press, Donetsk, 332 p.

2. Viktorov, S.D., Iofis, M.A. and Goncharov, S.A. (2005), Sdvizhenie i razrushenie gornykh porod, Nauka, M., 277 p.

3. Zhukov, V.E. (2001), «Ob odnoi strategicheskoi oshibke v razreshenii problemy razrabotki krutykh plastov», Ugol' Ukrainy, No. 7, pp. 6-10.

4. Selezen', A.L., Tomasov, A.G. and Andrushko, A.L. (1977), Podderzhanie podgotovitel'nykh vyrabotok pri razrabotke krutykh plastov, Nedra, Moskva, 205 p.

5. Radchenko, V.V., Medvedev, E.N. and Kuz'menko, N.S. (2010), Predotvrashchenie travmatizma ot obvalov $i$ obrushenii na ugol'nykh shakhtakh, K., 372 p.

6. Shashenko, A.N., Pustovoitenko, V.P. and Sdvizhikova, Ye.A. (2016), Geomekhanika, Naukoviy druk, K., 528 p.

7. Borisov, A.A. (1980), Mekhanika gornykh porod i massivov, Nedra, M., 360 p.

8. Liashok, Ya., Iordanov, I., Chepiga, D. and Podkopaiev, S. (2018), «Experimental studies of the seam openings competence in different methods of protection under pitch and steep coal seams development», Mining of Mineral Deposits, Vol. 12, Issue 4, pp. 9-19.

9. Podkopaev, S.V., Konopel'ko, E.I., Chepiga, D.A i dr. (2018), «Issledovanie proyavlenii gornogo davleniya v podgotovitel'nykh vyrabotkakh s uchetom zhestkosti okhrannykh sooruzhenii», Visti Donec'kogo girnychogo instytutu, No (42), pp. 84-95.

10. Rzhanitsyn, R.A. (1982), Stroitel'naya mekhanika, Vysshaya shkola, M., 398 p.

11. Sokolovskii, V.V. (1969), Teoriya plastichnosti, Vysshaya shkola, M., 608 p.

12. Barant, Z.P. and Cedolin, L. (2010), «Stability of structures: elastic, inelastic, fracture, and damage theories», World Scientific Publishing Co. Pte. Ltd., 1039 p.

13. Dakhakhi, W. (2010), Theory of Structures, Dal Al- Maaref, 446 p.

14. Marti, P. (2013), Theory of Structures: Fundamentals, Framed Structures, Plates and Shells, John Wiley Sons. Inc., Ernst Sohn GmbH\&Co. KG, 679 p.

15. Yarovaya, A.V. (2013), Stroitel'naya mekhanika. Statika sterzhnevykh system, BelGUT, Gomel', 447 p.

16. Leshchenko, A.P. (2008), Fundamental'naya stroitel'naya mekhanika uprugikh system, LKI, M., 976 p.

17. Iordanov, I.V., Simonova, Yu.I. and Polozhii, A.V., "Vliyanie podatlivosti opor na ustoichivost' porod krovli ugol'nogo plasta», Proceedings of the XIII International Scientific and Practical Conference International Trends in Science and Technology, Vol. 1, pp. 52-60.

18. Fekmistov, Yu.G. and Golovin, A.D. (2015), «Obosnovanie raspredeleniya davleniya na tseliki v osadochnykh gornykh porodakh», Litosfera, No. 6, pp. 130-135.

19. Khari, A., Baghbanan, A., Norouzi, S. and Hashemolhosseini, H. (2013), «Effects of fracture geometry and stress on the strength of a fractured rock mass», International Journal of Rock Mechanics\&Mining Sciences, No. 60, pp. 345-352.

20. Protosenya, A.G. and Verbil, P.E. (2017), «Raschet nesushchei sposobnosti i izuchenie anizotropii prochnostnykh kharakteristik mezhdukamernykh tselikov v blochnom gornom massive», Sbornik trudov (VIII Mezhdunarodnaya nauchno-prakticheskaya konferentsiya «Innovatsionnye napravleniya $v$ proektirovanii gornodobyvayushchikh predpriyatii: Geomekhanicheskoe obespechenie proektirovaniya i soprovozhdeniya gornykh rabot»), SanktPeterburg, pp. 219-225.

21. Chenlong, Wanga, Changsuo, Zhanga, Xiaodong, Zhaob and other (2018), «Dynamic structural evolution of overlying strata during shallow coal seam longwall mining», International Journal of Rock Mechanics and Mining Sciences, Vol. 103, pp. 20-32.

Подкопаев Сергей Викторович - доктор технических наук, профессор кафедры «Охрана труда» Государственного высшего учебного заведения «Донецкий национальный технический университет», г. Покровск, Украина.

Научные интересы:

- подземная разработка полезных ископаемых.

ORCID: 0000-0002-3258-9601.

E-mail: spodkopaiev@aol.com

Гого Владимир Бейлович - доктор технических наук, профессор Государственного высшего учебного заведения «Донецкий национальный технический университет», г. Покровск, Украина.

Научные интересы:

- подземная разработка полезных ископаемых.

ORCID: 0000-0002-2239-4042 
Иорданов Игорь Вячеславович - кандидат технических наук, соискатель кафедры «Охрана труда» Государственного высшего учебного заведения «Донецкий национальный технический университет», г. Покровск, Украина.

Научные интересы:

- подземная разработка полезных ископаемых.

ORCID: 0000-0001-9991-781X

E-mail: gendir@eme.kiev.ua

Положий Антон Витальевич - аспирант кафедры «Разработка месторождений полезных ископаемых» Государственного высшего учебного заведения «Донецкий национальный технический университет», г. Покровск, Украина

Научные интересы:

- подземная разработка полезных ископаемых

E-mail: anpolozhii@gmail.ru

Симонова Юлия Игоревна - аспирант кафедры «Разработка месторождений полезных ископаемых» Государственного высшего учебного заведения «Донецкий национальный технический университет», г. Покровск, Украина.

Научные интересы:

- подземная разработка полезных ископаемых

E-mail: yuliia.simonova@donntu.edu.ua

ORCID: 0000-0002-9192-7850. 